\title{
HIPNOSE, DOR E SUBJETIVIDADE: CONSIDERAÇÕES TEÓRICAS E CLÍNICAS
}

\author{
Maurício da Silva Neubern
}

\begin{abstract}
RESUMO. O presente artigo visa propor uma abordagem clínica e qualitativa para a compreensão das relações entre hipnose e dor a partir da noção de subjetividade. Partindo de uma crítica às metodologias estatísticas, três pontos são discutidos nesse sentido. Primeiramente, a dor é concebida como um processo subjetivo organizado em termos de configurações, sentidos, emoções e significados que são construídos a partir das ações do sujeito em seus respectivos cenários de inserção social. Em seguida, é ressaltada a relação entre hipnose e dor, conferindo-se destaque aos processos intersubjetivos da comunicação e da relação entre terapeuta e sujeito. O terceiro tópico destaca a importância da singularidade, que deve abranger tanto a compreensão da dor quanto a construção das intervenções hipnóticas. O artigo é concluído enfatizando a relevância das noções de subjetividade e sujeito no que se refere às complexas relações entre dor e hipnose no contexto clínico.
\end{abstract}

Palavras-chave: Hipnose; dor; psicologia clínica.

\section{HYPNOSIS, PAIN AND SUBJECTIVITY: THEORETICAL AND CLINICAL CONSIDERATIONS}

\begin{abstract}
The present article aims to propose a qualitative and clinical approach to the comprehension of the relationship between hypnosis and pain, taking as a reference the notion of subjectivity. Having a criticism of the statistical methodologies as a starting-point, three other points are discussed in that sense. Firstly, the pain is conceived as a subjective process, organized in terms of configurations, senses, emotions and meanings that are built in the actions of the subject in his or her respective social insertion sceneries. Secondly, the relationship between hypnosis and pain is emphasized, giving a highlight to the intersubjective processes that exist in the communication and relationship between therapist and subject. The third point accentuates the importance of the singularity that should range the comprehension of pain, as well as the construction of hypnotic interventions. The article is concluded by emphasizing the relevance of subjectivity and subject notions in what regards the complex relationships between pain and hypnosis in the clinical context.
\end{abstract}

Key words: Hypnosis; pain; clinical psychology.

\section{HIPNOSIS, DOLOR Y SUBJETIVIDAD: CONSIDERACIONES TEÓRICAS Y CLÍNICAS}

RESUMEN. El presente artículo tiene por objetivo proponer um abordaje clínico y cualitativo para la comprensión de las relaciones entre hipnosis y dolor a partir de la noción de subjetividad. Partiendo de una crítica a las metodologías estadísticas, se discuten básicamente tres puntos. En primer lugar, se considera el dolor como un proceso subjetivo organizado en términos de configuraciones, sentidos, emociones y significados, los cuales son construidos a partir de las propias acciones del sujeto en sus diversos escenarios de inserción social. A continuación, se tematiza la relación entre hipnosis y dolor, destacándose los procesos intersubjetivos de la comunicación y de la relación entre terapeuta y sujeto. En el tercer tópico se destaca la importancia de la singularidad que debe alcanzar tanto la comprensión del dolor como la construcción de las intervenciones hipnóticas. El artículo termina enfatizando la relevancia de las nociones de subjetividad y sujeto en el ámbito de las complejas relaciones entre dolor e hipnosis dentro del contexto clínico.

Palabras-clave: Hipnosis; dolor; psicología clínica.

Embora a tradição clínica na hipnose date de longo tempo, desde os magnetizadores do século XVIII e os hipnólogos do século XIX, existe na atualidade uma forte tradição de pesquisa quantitativa, considerada por alguns autores como a hipnose científica (Barber, 1996; Hilgard \& Hilgard, 1994). Tal perspectiva, que se coloca de forma exclusiva sob a chancela do termo ciência, traz contribuições

* Doutor em Psicologia, professor Adjunto do Instituto de Psicologia da Universidade de Brasília. 
significativas sobre o assunto, principalmente no que se refere ao desenvolvimento de parâmetros gerais para a avaliação da dor e do processo hipnótico em si. Assim, é possível considerar que a intervenção de um profissional de saúde - por exemplo, do psicólogo ganha certa praticidade, seja diante das respostas dadas a uma escala, seja diante de estudos epidemiológicos quanto a certas populações e os tipos específicos de dor (Patterson \& Jensen, 2003). Questões gerais referentes a gênero, idade, classe social, como também dores relacionadas a doenças como câncer e enxaqueca (Barber, 1996; Guimarães, 1999), ou ainda a fibromialgia, de recente interesse (Nogueira, Lauretti \& Costa, 2005), podem ser analisadas de maneira pertinente considerando-se as informações daí oriundas.

Entretanto, semelhantes perspectivas apresentam também diversas limitações, geralmente não discutidas pelos seus proponentes, pois estão associadas a modelos estatísticos de pesquisa. Os processos hipnóticos são concebidos em função de padrões gerais, deduzidos a partir da resposta a escalas e quantificáveis de maneira a conceber níveis de sugestionabilidade (Hilgard, 1967). Assim, enquanto se concebe que o nível de sugestão atingido por um sujeito permita as intervenções com vista à dor, desconsidera-se a dimensão singular da experiência hipnótica, de maneira que a vivência, as emoções e construções de sentido deste sujeito são excluídas das considerações e do aprofundamento da pesquisa. Ao mesmo tempo, a concepção da dor também se centra num conjunto de critérios externos ao sujeito (Guimarães, 1999; Patterson \& Jansen, 2003), em que as respostas coletadas por escalas ou observações de comportamento procuram descobrir seus padrões sem, contudo, dialogar com sua experiência. Nesse sentido, vale considerar que a simples inclusão de temas referentes à cultura ou ao meio social não permite tal aprofundamento, uma vez que a ênfase recai sobre dados exteriores ao sujeito, e não nas construções singulares e da experiência subjetiva que é perpassada pelo sociocultural.

Sendo assim, a proposta do presente trabalho é apresentar uma perspectiva clínica e qualitativa para a compreensão da relação entre hipnose e dor a partir da noção de subjetividade (Gonzalez Rey, 2007; Neubern, 2004a) ${ }^{1}$. Nesse sentido, a obra de Erickson

1 O termo subjetividade será tomado de Gonzalez Rey (2007), que a considera como a constituição psíquica do sujeito e se constitui em termos de sentidos, configurações e processos emocionais que se desenvolvem na ação social deste nos cenários em que toma parte. A subjetividade organiza-se em configurações, isto é, sistemas que integram
(Erickson \& Rossi, 1979) ocupará um lugar central, pois, embora esse estudioso não tenha desenvolvido uma teoria sobre a subjetividade, suas concepções possuem muitas aproximações com relação ao tema aqui discutido, seja na concepção da dor em termos de experiência, seja na compreensão da hipnose como um processo singular e relacional. Inicialmente, a dor será concebida como uma experiência subjetiva que se organiza de modo configuracional em termos de sentidos, emoções e significados que se desenvolvem a partir da inserção do sujeito nos diversos cenários sociais em que toma parte. Em seguida, será ressaltado o potencial terapêutico da hipnose como um recurso de grande valia para a modificação da experiência da dor, enfatizando-se as experiências cotidianas na produção da hipnose bem como sua dimensão interativa e comunicacional (Erickson, 1966; 1980; 1983). Por fim, será destacada a importância da singularidade no processo clínico, tanto para a compreensão da subjetivação da dor como para o desenvolvimento das intervenções hipnóticas (Erickson \& Rossi, 1980).

\section{A DOR PROCESSO SUBJETIVO}

A tradição médica, a partir dos séculos XVIII e XIX, buscou associar suas práticas ao projeto moderno de ciência, de maneira que o corpo humano e suas expressões patológicas passaram a ser concebidos, em grande parte, a partir de relações lineares de causa e efeito (Stengers, 1999). Tal perspectiva, apesar das numerosas controvérsias que ainda gera, constitui-se num referencial dominante entre os pesquisadores e profissionais de saúde que, em seus respectivos campos, buscam compreender as possíveis causas de uma doença na intrincada rede de relações do organismo humano. O sintoma é, portanto, expressão de algum processo subjacente, e as intervenções terapêuticas devem buscar aliviá-lo ou suprimi-lo e, quando possível, eliminar suas causas. Sintomas ou sinais como a dor podem possuir diversas causas, o que exige do médico considerável perspicácia para efetivar um bom diagnóstico, ou seja, um diagnóstico que permita estabelecer relações entre as expressões dolorosas e o que esteja por trás delas.

$\mathrm{O}$ que se verifica em semelhante proposta é a efetivação de uma série de clivagens típicas do projeto moderno de ciência (Stengers, 1995; 1999). O corpo é assemelhado a um laboratório, onde as influências

processos simbólicos e emocionais e se modificam ao longo da trajetória do sujeito. 
indesejáveis e subjetivas, capazes de contaminar a validade do saber médico, são afastadas ou pretensamente controladas. Assim, o corpo se torna uma entidade impessoal e sem história, uma entidade mecânica, dessubjetivada e inerte, sendo eleito como o terreno confiável em que o conhecimento científico pode se fazer triunfante. Não há um sujeito que adoece e vive uma dor, mas sim, um corpo desvitalizado e despersonalizado, onde os sinais típicos de uma entidade universal, a doença, se expressam diante do médico. Além disso, este corpo é isolado do intercâmbio social e cultural do sujeito, de maneira que as trocas simbólicas e emocionais que nele se expressam são, geralmente, ignoradas ou tidas como irrelevantes no que se refere à compreensão científica da doença e da dor (Gonzalez Rey, 2005; Nathan, 1999). Desse modo, o sujeito e a doença são reduzidos a seu substrato biológico, desprovidos de qualquer subjetividade e, ao mesmo tempo, constituem-se como palco de relações lineares e controladas bem ao gosto do rigor de ciência típico do laboratório. A fala, a emoção, a história e o símbolo ligados à dor são convertidos em sinais secundários ou apenas ignorados em sua complexidade (Stengers, 1999). É justamente esse corpo dócil e inerte, fornecedor de respostas pretensamente objetivas, que oferece a base para a hipnose positivista, cujo rigor é pretensamente validado por meio de procedimentos quantitativos.

Por outro lado, na perspectiva aqui adotada (Erickson \& Rossi, 1979; Gonzalez Rey, 2007; Neubern, 2004), compreende-se que a dor é um processo subjetivo ${ }^{2}$ no sentido amplo e complexo que tal expressão permite ${ }^{3}$. Ela é vivida por um sujeito e se configura na construção de sentidos e processos subjetivos complexos a partir das trocas socioculturais

2 Compreende-se aqui a dor como um processo subjetivo e complexo. Ela se caracteriza por uma experiência ancorada no corpo do sujeito que implica em uma sensação aversiva ou produtora de algum sofrimento. $\mathrm{O}$ corpo não consiste em uma entidade a parte do sujeito, mas num momento de constituição de sua subjetividade, o que explica que mesmo sem existir objetivamente, como no caso dos membros fantasmas, ainda_há uma construção subjetiva de um braço ou perna que sofre uma dor. Porém, independentemente de sua causalidade, a dor se configura também por meio de emoções, sentidos e significados e está ligada tanto à história como às trocas socioculturais do sujeito.

3 Em termos práticos, é importante considerar que esta proposta clínica qualitativa não dispensa a abordagem causalista de origem médica. Apenas questiona a exclusão da subjetividade que ela promove. Assim, um paciente que busque auxílio hipnótico queixando-se de uma dor deve ser encaminhado ao médico, uma vez que a intervenção hipnótica não visa à cura da causa, mas à reconfiguração da experiência subjetiva (Carvalho, 1999). em que este sujeito toma parte. A expressão de dor de uma pessoa, destarte, não consiste num conjunto de sinais indicativos de entidades universais que se manifestam numa massa impessoal, pois este corpo é constitutivo de um sujeito psicológico concreto e é indissociável da vivência de suas emoções, da construção de sua história, de suas relações sociais, de sua inserção na cultura e de sua maneira de construir sentidos sobre si e o mundo. Sendo assim, o foco do trabalho psicoterápico não se centra na busca de relações causais, mas na compreensão dos processos complexos de subjetivação que se constroem na vivência dolorosa do sujeito. Em outras palavras, a dor não pode ser desvencilhada do cotidiano da pessoa, mas deve ser compreendida na subjetivação que decorre de sua participação nos diversos cenários sociais em que atua.

Conforme se pode observar, essa subjetivação da dor implica em grande variedade de processos que remetem a temas comuns do cotidiano do sujeito (Carvalho, 1999; Zeig \& Geary, 2001). Há situações em que a dimensão temporal envolve todo um aprendizado do sujeito, que, na expectativa de uma dor recorrente, acaba por antecipar sua ocorrência (Erickson, 1966). A perspectiva de morte, no caso das doenças terminais, e as severas limitações impostas à sexualidade, costumam contribuir para um aumento nada desprezível do sofrimento do sujeito, o que coincide com a intensificação da dor (Erickson, 1959; 1966). Noutras circunstâncias, as relações sociais invasivas ou desqualificantes parecem intensificar o processo doloroso (Neubern, 2004b) e, em outras ainda, situações como a aposentadoria por doença por alguma dor incapacitante aparecem com frequência no cenário subjetivo dos sujeitos (Haley, 1991). Nestes casos, que seguidamente se fazem acompanhar de considerável isolamento social e perda de perspectivas futuras, não é incomum a associação com processos depressivos. Em suma, sexo, emprego, morte, religião e relacionamentos são temas comumente subjetivados na experiência dolorosa do sujeito, o que remete à necessidade de uma compreensão mais abrangente sobre a dor, sendo esta contextualizada em termos da subjetivação que ocorre no seu dia-a-dia.

Do exposto decorre a necessidade de um aporte teórico que possa oferecer referências para integrar as informações que emergem de diferentes processos associados à experiência dolorosa (Gonzalez Rey, 2005). Geralmente, as pesquisas sobre dor partem de uma ótica quantitativa e possuem, basicamente, duas grandes limitações. A primeira é a restrição à coleta de respostas extraídas por meio de questionários e escalas, o que leva a considerar a dor como um 
fenômeno em si, uma entidade objetiva e independente de qualquer abordagem teórica. Não obstante, uma vez que a dor remete a uma construção processual e complexa, uma pesquisa ou prática clínica aprofundada sobre ela não pode se restringir a respostas específicas, mas necessita de uma abordagem teórica abrangente, que permita dialogar com a riqueza dessas construções, as quais obedecem a processos qualitativos singulares e não a uma ordem estatística. É por meio de um processo interpretativo, inseparável da relação terapêutica, que o terapeuta integra informações aparentemente distintas e pode conceber a complexidade dos processos ligados a uma experiência de dor, já que dessa maneira torna-se possível a compreensão da singularidade dos sujeitos e de suas contradições.

\section{HIPNOSE E DOR}

Embora a hipnose tenha tido uma longa tradição clínica de práticas ligadas ao alívio e tratamento da dor, o surgimento dos anestésicos químicos na metade do século XIX contribuiu significativamente para a perda de espaço de suas aplicações neste campo por um longo tempo ${ }^{4}$ (Méheust, 1999). Em consequência de semelhante perda de interesse, a hipnose passou a ser pouco pesquisada enquanto recurso de auxílio no alívio de processos dolorosos, e muitas indagações permaneceram sem uma pesquisa mais aprofundada nesse sentido. Somando-se a isso as dificuldades inerentes à compreensão do processo hipnótico em si (Stengers, 2001), concebe-se que existem ainda muitas indagações que dividem os pesquisadores e não permitem uma compreensão mais precisa sobre os mecanismos e meios de ação dos processos hipnóticos, como é o caso da contradição entre estado alterado e jogo de papéis (Spanos, 1986; Stengers, 2001).

Não obstante, as contribuições de Erickson (1966; 1980; 1983 Erickson \& Rossi, 1979) se mostram interessantes devido à complexidade que comportam. Para ele, os fenômenos hipnóticos procedem dos aprendizados e processos da vida cotidiana e não se constituem como expressões distintas do repertório desenvolvido pelos sujeitos ao longo de sua história.

4 A grande tradição de magnetizadores anestesistas teve expoentes como Puységur, Cloquet, Eisdalle e Elliotson. Com o surgimento dos anestésicos, em 1846, a hipnose, herdeira do magnetismo animal, perdeu muito espaço nesse campo de intervenções. Seu interesse só foi retomado no século XX por pesquisadores como Chertok, Erickson e Hilgard.
Dessa maneira, sua forma de produzir com a pessoa determinado fenômeno hipnótico deveria necessariamente considerar os recursos já trazidos por ela que pudessem ser ampliados e assim utilizados como instrumento para lidar com determinada experiência dolorosa. Por essa razão, um acontecimento aparentemente simples, como um esquecimento, comum na vida de um sujeito, poderia ser levado a se transformar numa amnésia seletiva sobre determinados momentos de uma experiência dolorosa (Erickson, 1980), bem como as divagações típicas de uma pessoa que está num lugar mas projeta seu pensamento constantemente em outra situação, poderia ser transformada em uma dissociação na qual a mente fosse para outro lugar enquanto o corpo ficasse ali para ser tratado pela intervenção médica, psicológica ou odontológica (Erickson, 1966).

Por outro lado, Erickson (citado em Neubern, 2004b), ao considerar a hipnose como uma forma de transmitir idéias, achava que a relação entre o terapeuta e o cliente poderia constituir-se como um poderoso instrumento de influência, capaz de auxiliar na reconfiguração da experiência dolorosa deste último. Para ele, a reconstrução de sentidos proposta pela terapia não estaria limitada a um insight intelectual, mas a uma mudança efetiva na vivência da dor e nas próprias percepções corporais da pessoa. Assim, Erickson (1957) poderia se utilizar de algum tema de interesse para o sujeito e contar-lhe uma história sobre o assunto, conectando a tal história uma série de sugestões de alívio, conforto e dissociação, como se deu no caso de Joe, o florista (Haley, 1991). Para poder prender a atenção deste paciente, em estado terminal de câncer, Erickson (Haley, 1991) contou-lhe a história do desenvolvimento de um pé de tomate, sendo que, em determinados trechos da história, modificava o tom de sua voz ao falar do conforto, da tranquilidade e da naturalidade do desenvolvimento da planta. Joe, possivelmente associando seu corpo ao pé de tomate, aprendeu a desenvolver um transe em que, quando as dores começassem a se intensificar, era desencadeado um processo dissociativo que as reduzia consideravelmente, colocando-as sob relativo controle e permitindo-lhe aproveitar seus últimos dias sem a necessidade de ser sedado.

\section{CLÍNICA DA SINGULARIDADE}

Conforme o exposto, a terapia de sujeitos que trazem alguma demanda ligada à dor não pode possuir protocolos fixos, já que a experiência dolorosa e a própria relação clínica dependem do momento e da 
singularidade das pessoas envolvidas. Nesse sentido, a postura do terapeuta apresenta duas facetas altamente integradas, que necessitam ser devidamente trabalhadas para que a terapia atinja seus objetivos.

Por um lado, é importante que o terapeuta esteja atento ao processo relacional, especialmente no que se refere à forma de estabelecer um vínculo com o sujeito (Gonzalez Rey, 2007). Aqui o terapeuta não enxerga apenas o outro, mas se enxerga na relação com o outro e fica muito atento à dinâmica dos papéis que ambos desenvolvem na coreografia da relação. Pessoas que vivenciam dores intensas podem circular por papéis que incluem vitimização, agressividade, colaboração, revolta, dentre outros, o que acaba requerendo do terapeuta um papel que dê continência a essas expressões e propicie sua inclusão no processo terapêutico (Zeig, 1994). Não há regra fixa no que se refere a essa dinâmica, pois uma pessoa que se encontre revoltada pode ser beneficiada por um terapeuta maternal enquanto outra que se expressa no mesmo papel pode se engajar na terapia a partir do contato com um terapeuta autoritário. O que realmente importa é que o papel adotado pelo terapeuta ofereça, ao mesmo tempo, acolhimento do sofrimento trazido pelo sujeito e possibilidades terapêuticas aceitáveis e possíveis para ele. À medida que o sujeito percebe que sua dor não é uma entidade independente e inatingível, mas pode ser influenciada de algum modo, e que existe a possibilidade de ganhos significativos nesse sentido, sua integração à terapia tende a se concretizar. Uma vez que esteja engajado no processo, tem-se efetivada a parte mais importante do contrato terapêutico, que é exatamente a criação de um vínculo emocional com o terapeuta e com a proposta oferecida pela terapia (Erickson \& Rossi, 1979). Questões como aceitação da ajuda, número de encontros, honorário (quando em consultórios privados) e tempo das sessões constituem a parte objetiva do contrato e devem ser utilizadas para que essa ligação emocional se concretize, pois, do contrário, as intervenções provavelmente serão ineficazes.

Muito ligada ao anterior, encontra-se a construção do terapeuta quanto à subjetivação da experiência dolorosa. Estas costumam implicar em grandes transformações na vida do sujeito, que variam de diversas formas de limitação a questões de considerável teor existencial. Nesse sentido, um dos primeiros pontos que se devem compreender é a autoimagem (Erickson citado em Haley, 1985) que a pessoa desenvolve e sua relação com a experiência dolorosa $^{5}$. Assim, o terapeuta deve estar atento a um conjunto de processos de construção de sentido que o sujeito desenvolve a partir de sua dor, como a apreciação de seu próprio corpo, de sua posição diante dos outros, de suas concepções de vida e de como ele constrói sua imagem diante de temas como sua família, sua rede social, sua religião, sua profissão e suas perspectivas de futuro. As experiências de dor, comumente, configuram diferentes processos simbólicos e emocionais que precisam ser compreendidos como integrantes de uma dinâmica complexa e, por vezes, contraditória do sujeito quanto a si mesmo e às pessoas com quem se vincula (Gonzalez Rey, 2007; Neubern, 2004a).

Nesse sentido, vale destacar que certas expressões metafóricas trazidas pelos sujeitos constituem-se em excelentes indicadores sobre a construção que operam em sua autoimaem, como nos exemplos a seguir (Erickson \& Rossi, 1979; Haley, 1985, 1991). Uma mulher refere-se a sua dor "como se tivesse sido atropelada", no entanto não se dá conta de que, em suas relações mais íntimas com amigos e familiares, ela costuma assumir uma posição na qual, geralmente, é desqualificada ou agredida pelo outro. Não parece ser por acaso que suas dores surjam, na grande maioria das vezes, após ásperas discussões com alguém próximo. Outra pessoa, que padece de dores crônicas na região superior da coluna, diz sentir que "carrega o mundo nas costas", principalmente o de sua família, pois é sempre ela quem assume a responsabilidade, as contas e as dívidas de seus parentes próximos, mesmo quando estes já são adultos. Um homem, que devido a um acidente de trabalho é aposentado de forma precoce, diz que "sua vida parou" e que não há muito mais a fazer a não ser esperar pela morte. As consequências do acidente o isolaram de suas principais redes sociais, onde ele possuía atividades vitais de seus projetos de vida, o que coincidiu com uma severa depressão e a sofrida sensação de um tempo que não mais andava e fluía, trazendo-lhe a vivência de uma dor interminável. Tais metáforas são importantes indicadores sobre a criação de realidades a partir da dor, podendo ser utilizadas pelo terapeuta tanto na compreensão da construção de sentido quanto como ferramenta para a construção das

\footnotetext{
5 Por auto-imagem, Erickson (citado em Haley, 1985) considerava o conjunto de construções que o sujeito desenvolve sobre si mesmo. Trata-se de um processo complexo que envolve componentes históricos, emocionais e sócio-culturais, como a própria postura ativa do sujeito em seu cotidiano. Tais construções, em muitos de seus momentos, são inconscientes.
} 
intervenções terapêuticas (Carvalho, 1999; Erickson, 1980).

Ao mesmo tempo, a construção do terapeuta sobre a subjetividade da pessoa necessita também focar suas possibilidades hipnóticas, que, na maior parte das vezes, é desconhecida da própria pessoa. Fazendo-se coro com Erickson (1959), concebe-se que a experiência hipnótica remete a um conjunto de processos singulares e típicos da pessoa e que, em consequência, cabe ao terapeuta buscar compreender a forma particular de sua expressão. Diferentemente de procedimentos clássicos, que buscam avaliar a sugestionabilidade por meio de escalas padronizadas (Hilgard, 1967), o terapeuta centra sua avaliação naquele sujeito particular e busca compreender, por meio de uma leitura teórica e qualitativa, indicadores sobre suas possibilidades hipnóticas. Sua forma de construção de raciocínio (se linear ou mosaico), de expressão da linguagem (se concreta ou metafórica), seus sentidos físicos dominantes (auditivo, visual, olfativo ou cinestésico), seu modo de relação dominante no momento (vítima, confronto, colaboração, fuga) são alguns dos indicadores significativos do funcionamento hipnótico do sujeito (Zeig, 1994).

Tais indicadores, além de oferecerem informações de grande relevância para a construção das intervenções, remetem o terapeuta a uma compreensão sobre a relação da pessoa com seus processos inconscientes ${ }^{6}$ (Erickson \& Rossi, 1980), a partir dos quais poderão ser desenvolvidos os fenômenos hipnóticos. Conforme já mencionado, estes se fundamentam em recursos desenvolvidos na vida cotidiana das pessoas e podem ser particularmente úteis na reconfiguração da experiência dolorosa, como nas situações a seguir. A dor, frequentemente, altera a experiência de tempo da pessoa de variadas formas, podendo ser vivida como interminável ou levando a pessoa a temê-la de tal modo que a antecipa com maior frequência (Erickson, 1959). Em certos casos de fibromialgia, é comum que a intensidade da dor seja associada à depressão, o que leva os sujeitos a uma construção pessimista sobre sua história e sobre seu futuro. Assim, diante de uma pessoa cuja experiência de tempo é preponderante em sua dor, o terapeuta pode se utilizar de uma série de fenômenos de tempo,

6 O inconsciente de Erickson (Erickson \& Rossi, 1980) não consiste em uma topografia da mente onde ficam armazenados conteúdos de conflitos indesejáveis à consciência. Para ele, no inconsciente existem processos de aprendizado de ordens diversas além do sofrimento, como potenciais e recursos que podem ser utilizados de modo favorável a partir da criação de um contexto terapêutico. como sugestão pós-hipnótica e regressão de idade. Com a distorção do tempo, é possível levar o sujeito a prolongar os momentos de ausência de dor e aumentar a velocidade dos momentos nos quais esta se faz presente, da mesma forma que a regressão de idade pode favorecer uma retrospectiva histórica que encontre vivências e situações capazes de quebrar a lógica pessimista e propiciar novas projeções.

Em outras situações, há pessoas que apresentam dominância do sentido cinestésico na maneira como vivenciam suas dores, de modo que a forma como desenvolvem sua linguagem é altamente impregnada de termos referentes a sensações corporais, qualificando a dor como algo que corta, penetra, fura, queima, dentre outras representações. É possível que fenômenos sensórios, como anestesia e analgesia, sejam de grande valia em tais casos, de maneira que a linguagem do terapeuta necessita enfatizar com detalhes as mudanças nas sensações corpóreas. Assim, para uma pessoa que relate apreciar bons momentos ao sol, o conto de uma história que enfatize a ação agradável do sol tocando e queimando delicadamente a pele de alguém pode trazer mudanças significativas no conjunto de sensações corporais da pessoa ou mesmo favorecer o desenvolvimento de uma analgesia parcial ou total.

Também não é raro constatar que algumas pessoas acometidas por dores intensas desenvolvam processos dissociativos como forma de autoproteção: algumas, simplesmente, esquecem uma parte ferida do corpo; outras se projetam para outro lugar no tempo e no espaço, deixando seu corpo ali e sua mente a se entreter com outros assuntos; outras ainda chegam a ter experiências relatadas como ausências que geralmente parecem estar fora de seu controle deliberado e se impor a elas (Erickson, 1966). Em todos esses casos, as dissociações funcionam como o desencadeamento, em geral espontâneo, de recursos que buscam aliviar a experiência dolorosa, de modo que tais recursos, no estado habitual, costumam ficar longe do alcance consciente dos sujeitos. Semelhante ruptura, que favorece a emergência de processos inconscientes, é um dos fenômenos mais característicos da hipnose, estando na base da produção dos outros fenômenos. Desse modo, enquanto a mente da pessoa se divide e uma parte se ocupa de algum tema que seja interessante para o sujeito, o inconsciente é ativado e seus recursos utilizados para a mudança da experiência dolorosa. Ela se transporta para uma vivência agradável já experimentada junto à natureza, por exemplo, enquanto os processos desencadeados sob novas sugestões reduzem consideravelmente aquela dor, 
resgatando sensações de alívio e conforto. Uma ruptura desse tipo possui um impacto considerável sobre a subjetividade do sujeito, de maneira a promover modificações significativas nas referências e configurações que o sujeito desenvolve sobre si e sua dor.

Em suma, a clínica da dor refere-se a um processo em que a singularidade da pessoa possui um papel fundamental, pois é a partir dela que as intervenções devem ser desenvolvidas. Tal singularidade também remete à importância de que o contexto terapêutico contemple as necessidades de mudança que o sujeito traz consigo, mas nem sempre percebe, já que sua experiência dolorosa pode levá-lo à construção de sentidos de desesperança e falta de perspectivas. Comumente tais pessoas expressam não possuir mais esperança de inserção profissional, de relacionamentos amorosos, de realização de projetos de vida, de aceitação em suas redes sociais, enfim, de construções que apontam na direção da impossibilidade de qualquer forma significativa de realização. Daí a importância de que o terapeuta compreenda suas necessidades, bem como as configurações desenvolvidas em seu cenário e, ao mesmo tempo as ajude a construir possibilidades plausíveis para seu processo, ou seja, que reconheçam suas limitações, mas não deixem de propiciar mudanças capazes de favorecer a construção de soluções pertinentes em termos da subjetivação e das situações concretas do cotidiano.

\section{CONCLUSÃO}

A pertinência de se considerar a relação hipnose e dor de um ponto de vista clínico e qualitativo se dá principalmente pela tentativa de uma compreensão desses processos como integrantes da subjetividade humana (Gonzalez Rey, 2007; Neubern, 2004a). É possível considerar que as pesquisas estatísticas se referem a padrões e escores gerais, e não a processos de construção de sentidos e emoções que emergem na experiência cotidiana dos sujeitos. Isso não significa que tais pesquisas devam ser abandonadas, uma vez que possuem sua pertinência no que se refere à pesquisa de padrões gerais e grandes populações; porém nem sempre parece existir clareza quanto à compreensão sobre as limitações e possibilidades de sua proposta metodológica, que não raro é eleita como representante exclusiva do conhecimento científico sobre os processos humanos.
Desse modo, é necessário considerar que a pesquisa, como também a intervenção clínica, sobre as complexas relações entre hipnose e dor, deve abranger essas zonas de sentido que possuem uma importância capital na sua compreensão, sob pena de permanecer deficitária. Dito de outro modo, a dor se organiza subjetivamente em termos de configurações e sentidos, de emoções e significados, e possui uma estreita relação, que não se define estatisticamente, com as redes sociais da pessoa (Carvalho, 1999; Zeig \& Geary, 2001). Ela implica em aprendizados, vivências e percursos históricos e não se constitui como uma entidade estática e isolada, mas como um processo que se constrói e se influencia pela própria ação do sujeito em relação a si mesmo e ao outro. De maneira similar, a hipnose se constitui no seio das interações humanas, e a riqueza dos processos relacionais que aí tomam parte não se restringe a padrões fixos, mas inclui processos de influência, vínculo e comunicação que podem modificar de diversas formas a subjetivação das pessoas envolvidas (Erickson, 1980; Neubern, 2004a). Nesse sentido, vários autores a concebem como uma forma de interação muito mais próxima das relações cotidianas do que de padrões gerais e impessoais típicos da pesquisa estatística (Erickson, 1959; Melchior, 1998; Neubern, 2004a; Roustang, 1991).

É importante ressaltar que a pertinência de uma abordagem clínica e qualitativa também se faz presente devido à inclusão do sujeito (Erickson \& Rossi, 1979; Gonzalez Rey, 2007). Sendo assim, a compreensão da experiência subjetiva da dor, como do próprio tratamento, não se limita a um corpo isolado e impessoal, mas compreende alguém que gera sentidos sobre si e o mundo e que se insere em diversas contextos sociais que, por vezes, são afetados e influenciam essa dor. Mais que isso, a concepção de que a dor é vivida por um sujeito permite, via hipnose, acessar esse sujeito e estabelecer com ele um contrato terapêutico em que ele toma parte ativa no processo e rompe com a exclusividade de uma postura na qual apenas recebe instruções e medicamentos para assumir o papel de alguém que pode, até certo ponto, influenciar e modificar sua própria experiência dolorosa. Além de oferecer subsídios para um tema corrente em várias instituições de saúde - a adesão ao tratamento - tal perspectiva propicia mudanças significativas nas construções do sujeito sobre si mesmo, uma vez que sua participação ativa implica na mobilização de recursos oriundos de tanto sua própria subjetividade como de sua rede social. 
Por fim, é necessário destacar que uma proposta clínico-qualitativa como a aqui apresentada pode ser considerada como incoerente diante dos parâmetros científicos (Stengers, 1999), a que os métodos quantitativos costumam se referir de forma exclusiva. Por outro lado, compreende-se que noções tão marginalizadas ao longo da história da ciência, como subjetividade e sujeito (Santos, 1987), continuam trazendo problemas complexos para a possibilidade de uma pesquisa científica na psicologia. Isto porque, se são excluídos, como se dá nas propostas quantitativas, implicam numa profunda descaracterização do campo e dos processos estudados, e se são concebidos como pontos fundamentais destes, exigem modificações radicais no que se refere à própria noção de ciência. Em face de tal encruzilhada, o presente trabalho optou pela segunda via, que, por buscar uma compreensão mais complexa e coerente com o sujeito humano, encara o desafio, junto com vários autores (Gonzalez Rey, 2005; Neubern, 2004a; Roustang, 1991; Santos, 1987), de tecer profundos questionamentos epistemológicos sobre sua própria ciência.

\section{REFERÊNCIAS}

Barber, J. (1996). Hypnosis and suggestion in the treatment of pain. New York: WW. Norton.

Carvalho, M. (1999). Dor: Um estudo multidisciplinar. São Paulo: Summus.

Erickson, M. (1959). Further clinical techniques of hypnosis: the utilization techniques. American Journal of Clinical Hypnosis, 6, $293-307$.

Erickson, M. (1966). The interpersal hypnotic technique for symptom correction and pain control. American Journal of Clinical Hypnosis, 8, 198 - 209.

Erickson, M. (1980). An introduction to the study and application of hypnosis for pain control. In M. Erickson \& E. Rossi (org). The collected papers of Milton Erickson, MD (pp. 237 - 245).

Erickson, M. (1983). Healing in hypnosis. New York: Irvington.

Erickson, M., \& Rossi, E. (1979). Hypnotherapy: An exploratory casebook. New York: Irvington.

Erickson, M., \& Rossi, E. (1980). The collected papers of Milton $H$. Erickson, MD. New York: Irvington.

Gonzalez Rey, F. (2005). Subjetividade, complexidade e pesquisa em psicologia. São Paulo: Thomson.

Gonzalez Rey, F. (2007). Psicoterapia, subjetividade e pósmodernidade. São Paulo: Thomsom.
Guimarães, (1999). A dor na infância. Em M. Carvalho (org.). Dor: Um estudo multidisciplinar (pp 248 - 264). São Paulo: Summus.

Haley, J. (1985). Conversations with Milton Erickson. Changing individuals. New York: Triangle Press.

Haley, J. (1991). Uncommon therapy. New York: WW Norton.

Hilgard, E. (1967). A quantitative study of pain and its reduction through hypnotic suggestion. Proceedings of the National Academy of Science, 57, 1581 - 1586.

Hilgard, E., \& Hilgard, J. (1994). Hypnosis in the relief of pain. New York: Brunner/Mazel.

Méheust, B. (1999). Somnambulisme et médiumnité. Le défi du magnetisme animal. Paris: Synthélabo.

Melchior, T. (1998). Créer le Reel. Paris: Seuil.

Nathan, T. (1999). Manifeste pour une psychopatologie scientifique. Dans T. Nathan \& I. Stengers (org). Médecins et sorciers. (pp. 9 113). Paris: Synthélabo.

Neubern, M. (2004a). Complexidade e psicologia clínica: Desafios epistemológicos. Brasília: Plano.

Neubern, M. (2004b). Histórias que (não) curam: sobre narrativas em hipnose clínica. Psicologia: Ciência e Profissão, 3, 58 - 65.

Nogueira, C.; Lauretti, G., \& R. Costa. (2005). Avaliação duplamente encoberta da hipnose em fibromialgia. São Paulo Medical Journal, 14(suppl 1), 123.

Patterson, D., \& Jansen, M. (2003). Hypnosis and clinical pain. Psychological Bulletin, 129(4), 495 - 521.

Roustang, F. (1991). Influence. Paris: Minuit.

Santos, B. (1987). Um discurso sobre as ciências. Porto: Afrontamento.

Spanos, N. (1986). Hypnotic behavior: A social-psychological interpretation of amnesia, analgesia and "trance logic". The behavioral and brain sciences, 9, 449-502.

Stengers, I. (1995). L'invention des sciences modernes. Paris: Flammarion.

Stengers, I. (1999). Le médecin et le charlatan. In T. Nathan \& I. Stengers (org.). Médecins et sorciers. (pp. 115 - 161). Paris: Synthélabo.

Stengers, I. (2001). Qu'est-ce que l'hypnose nous oblige à penser? Ethnopsy. Les Monde Contemporain de la Guerison, 3, 13 - 68.

Zeig, J. (1994). Advanced techniques of utilization: an intervention, metamodel and the use of sequences, symptom words and figures of speech. In J. Zeig (org). Ericksonian methods. The essence of the story. (pp. 295 - 314). Levittown: Brunner/Mazel.

Zeig, J., \& Geary, B. (2001). Ericksonian approaches to pain management. In B. Geary \& J. Zeig (org). Handbook of ericksonian psychotherapy. (pp. 252 - 261). Phoenix: Milton Erickson Foundation Press.

Recebido em 20/11/2007 Aceito em 14/08/2008

Endereço para correspondência :

Maurício da Silva Neubern. Campus Universitário Darcy Ribeiro, Departamento de Psicologia Clínica (PCL), Instituto de Psicologia (IP), Universidade de Brasília (UnB) Cep 70910-900, Brasília-DF, Brasil. E-mail: mneubern@ @otmail.com 